\title{
Morphology and mixing of black carbon particles collected in central California during the CARES field study
}

\author{
Ryan C. Moffet ${ }^{1}$, Rachel E. O'Brien ${ }^{1,2, a}$, Peter A. Alpert ${ }^{3, b}$, Stephen T. Kelly ${ }^{2, c}$, Don Q. Pham ${ }^{1}$, Mary K. Gilles ${ }^{2}$, \\ Daniel A. Knopf ${ }^{3}$, and Alexander Laskin ${ }^{4}$ \\ ${ }^{1}$ Department of Chemistry, University of the Pacific, Stockton, CA 95211, USA \\ ${ }^{2}$ Chemical Sciences Division, Lawrence Berkeley National Laboratory, Berkeley, CA 94720, USA \\ ${ }^{3}$ Institute for Terrestrial and Planetary Atmospheres, School of Marine and Atmospheric Sciences, \\ Stony Brook University, Stony Brook, NY 11794, USA \\ ${ }^{4}$ Pacific Northwest National Laboratory, W. R. Wiley Environmental Molecular Sciences Laboratory, \\ Richland, WA 99354, USA \\ a present address: Department of Civil and Environmental Engineering, Massachusetts Institute of Technology, \\ Cambridge, MA 02139, USA \\ b present address: CNRS, UMR5256, IRCELYON, Institut de Recherches sur la Catalyse et l'Environnement \\ de Lyon, Villeurbanne 69626, France \\ ${ }^{\mathrm{c}}$ present address: Carl Zeiss X-ray Microscopy Inc., Pleasanton, CA 94588, USA
}

Correspondence to: Ryan C. Moffet (rmoffet@pacific.edu)

Received: 16 July 2016 - Published in Atmos. Chem. Phys. Discuss.: 20 July 2016

Revised: 27 October 2016 - Accepted: 2 November 2016 - Published: 23 November 2016

\begin{abstract}
Aerosol absorption is strongly dependent on the internal heterogeneity (mixing state) and morphology of individual particles containing black carbon (BC) and other non-absorbing species. Here, we examine an extensive microscopic data set collected in the California Central Valley during the CARES 2010 field campaign. During a period of high photochemical activity and pollution buildup, the particle mixing state and morphology were characterized using scanning transmission X-ray microscopy (STXM) at the carbon K-edge. Observations of compacted BC core morphologies and thick organic coatings at both urban and rural sites provide evidence of the aged nature of particles, highlighting the importance of highly aged particles at urban sites during periods of high photochemical activity. Based on the observation of thick coatings and more convex $\mathrm{BC}$ inclusion morphology, either the aging was rapid or the contribution of fresh BC emissions at the urban site was relatively small compared to background concentrations. Most particles were observed to have the $\mathrm{BC}$ inclusion close to the center of the host. However, host particles containing inorganic rich inclusions had the $\mathrm{BC}$ inclusion closer to the edge of the particle. These measurements of BC morphology and mixing state
\end{abstract}

provide important constraints for the morphological effects on BC optical properties expected in aged urban plumes.

\section{Introduction}

Aerosols have a direct effect on climate by scattering and absorbing solar radiation. Black carbon (BC), which results from the incomplete combustion of hydrocarbons from a variety of fuels, absorbs solar radiation across the visible spectrum, resulting in a warming effect (Bond et al., 2013; IPCC, 2013). BC is estimated to be the second most potent atmospheric warming agent, with carbon dioxide being the most potent. Reducing BC emissions would rapidly counteract the heating by greenhouse gases (Ramanathan and $\mathrm{Xu}, 2010$; Ramanathan and Feng, 2008; Rogelj et al., 2014). To predict the amount of cooling by removing $\mathrm{BC}$ from the atmosphere, the direct effect due to $\mathrm{BC}$ must be modeled using realistic assumptions.

Because of the insufficient knowledge of particle morphology, mixing state, and interactions with other atmospheric constituents, the radiative effect of $\mathrm{BC}$ is uncertain. Radia- 
(a)Pre-edge: $278 \mathrm{eV}$

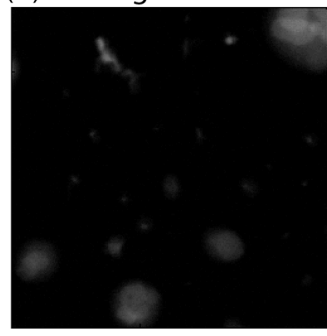

(c) $\mathrm{C}^{*} \mathrm{OOH}: 288.6 \mathrm{eV}$

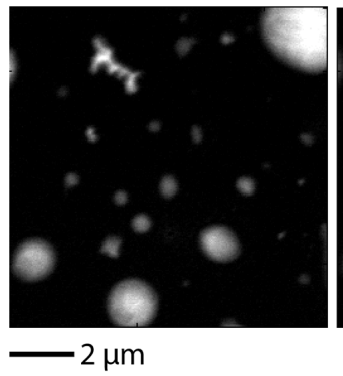

(b) $\mathrm{sp}^{2} \mathrm{C}^{*}=\mathrm{C}: 285.4 \mathrm{eV}$

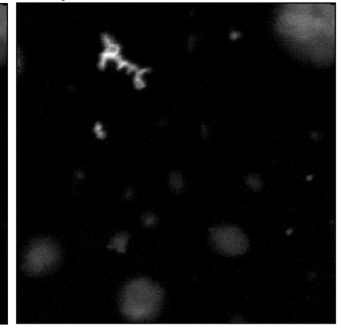

(d)Post-edge: 320 eV

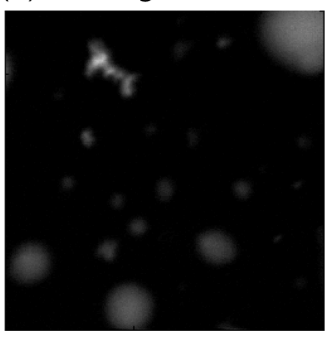

(e) Organic map

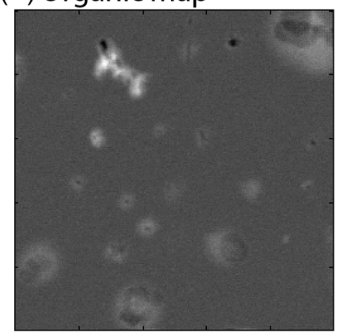

(g) BC map

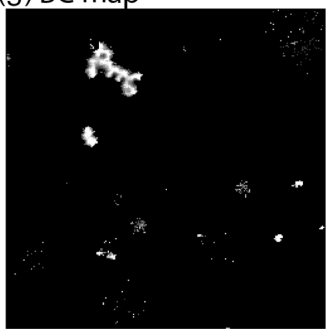

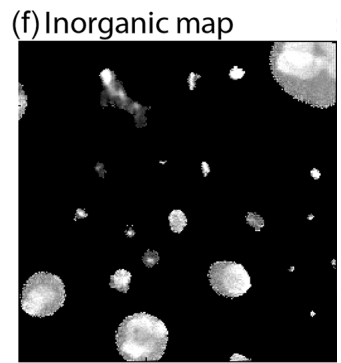

(h) Combined map

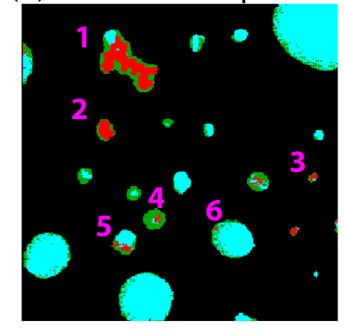

Figure 1. (a-d) Single energy images at 278, 285.4, 288.6, and $320 \mathrm{eV}$ representing the pre-edge, $\mathrm{C}^{*}=\mathrm{C} \mathrm{sp}^{2}$ carbon, $\mathrm{C} * \mathrm{OOH}$, and total carbon. (e) Organic map produced by subtracting the image at $278 \mathrm{eV}$ from the image at $288.6 \mathrm{eV}$. (f) Inorganic map produced by taking the ratio of the image at $278 \mathrm{eV}$ to the image at $320 \mathrm{eV}$ (pre-edge: total carbon). (g) $\mathrm{sp}^{2}$ carbon map derived by multiplying the ratio of $285.4 \mathrm{eV}$ to $320 \mathrm{eV}$ by a constant to give the percentage of $\mathrm{sp}^{2}$ bonds as described in Hopkins et al. (2007). (h) Combined maps derived from thresholding of maps; (e)-(g) red areas contain $\% \mathrm{sp}^{2}>35 \%$, green areas are organic dominant, and blue areas are non-carbonaceous inorganic dominant.

tive transfer models require knowledge about scattering and absorption cross sections and the angular dependence (phase function) of scattered light. Estimates of these parameters are obtained using Mie theory, which assumes particles are homogenous spheres. However, aerosols containing BC are frequently internally mixed. Hence, within the same particle, the $\mathrm{BC}$ is heterogeneously mixed with non-absorbing species (Adachi and Buseck, 2008; Moffet et al., 2013). To address the heterogeneous particle structure, the $\mathrm{BC}$ has been modeled as a centrally located sphere evenly coated by nonabsorbing material (Ackerman and Toon, 1981). Implementing this type of core shell theory in global modeling studies suggests a large warming due to the internal mixing of $\mathrm{BC}$ (Jacobson, 2001). Numerous recent studies indicate that assuming that the $\mathrm{BC}$ is located exactly in the center of the particle overestimates BC absorption (Adachi et al., 2007; Cappa et al., 2012). Several studies point out that a lower BC absorption is obtained by offsetting the $\mathrm{BC}$ inclusion from the center towards the particle edge; recent field studies confirm that the core-shell model may not be valid and that other modeling approaches are needed (Cappa et al., 2012; China et al., 2013). Alternate approaches include the Maxwell Garnett approximation as well as the discrete dipole approximation (DDA; Scarnato et al., 2013). The Maxwell Garnett is an "effective medium" approximation whereby an effective dielectric constant is calculated using the dielectric constants of the host and the inclusion. Effective medium ap- proaches still use Mie theory to generate cross sections and phase functions. Alternatively, DDA uses an array of dipoles with prescribed optical properties to calculate cross sections and phase functions. If enough dipoles are used with DDA, the calculation theoretically becomes exact but is computationally expensive. To test the validity of these theoretical approaches to calculating aerosol radiative properties, detailed morphological and chemical measurements are required at the individual particle level.

In this study, scanning transmission X-ray microscopy (STXM) is used to quantify the morphology and mixing state of $\mathrm{BC}$ containing particles collected from the Carbonaceous Aerosols and Radiative Effects Study (CARES). During the June 2010 CARES study, a comprehensive set of aerosol, gas, and meteorological parameters was measured (Moffet et al., 2013; Zaveri et al., 2012; Fast et al., 2012). The CARES field study focused on the chemical and physical properties of organic carbon and $\mathrm{BC}$ containing particles, and several reports have examined the characteristics of $\mathrm{BC}$ particles (Cappa et al., 2012; Cahill et al., 2012; Cazorla et al., 2013; Chakrabarty et al., 2014). Thus far, none report direct measurements of the chemical and morphological properties for a statistically significant number of BC particles. This report presents a microscopic analysis for a large number of BC particles $(\sim 1900 \mathrm{BC}$ containing particles out of a data set containing $\sim 20000$ particles) collected during selected dates of the CARES field campaign. This manuscript utilizes 
and builds upon the data set presented in two earlier studies (Moffet et al., 2013; O'Brien et al., 2015). Results presented here can be used to validate assumptions employed in optical and radiative transfer models.

\section{Experimental}

Samples of atmospheric particles were collected during the CARES campaign conducted in June 2010 in Central Valley, California. Field sites and sampling procedures are described in previous publications (Moffet et al., 2013; Zaveri et al., 2012) and are only briefly described here. Sampling occurred at two primary field sites: the first site was in the Sacramento urban area (T0 site) expected to have enhanced fresh emissions, and the second site was located $40 \mathrm{~km}$ east of T0 in the Sierra Nevada foothills (T1 site) expected to have enhanced aged aerosol. Samples utilized here were collected over 2 days (27 and 28 June) during a period of high temperatures and increased aerosol loadings over $\mathrm{T} 0$ due to high photochemical activity. $\mathrm{CO}$ tracer modeling indicated that significant transport from the San Francisco Bay Area affected the Sacramento site in the morning while the boundary layer was low. Later on in the day a larger fraction of emission at the T0 site was from the Sacramento metropolitan area. Similar contributions from the San Francisco Bay Area were modeled at T1; however, emissions from Sacramento constituted the largest source of emissions during this time period (Moffet et al., 2013; Fast et al., 2014). Aerosols were collected onto several substrates, including Si wafers for ice nucleation studies (Knopf et al., 2014), Si wafers containing $\mathrm{Si}_{3} \mathrm{~N}_{4}$ membrane windows (Moffet et al., 2013), and Formvar/carbon type B coated copper grids (Ted Pella, Redding, CA) using a time resolved aerosol collector (TRAC) (Laskin et al., 2003, 2006). After collection, the samples were sealed and stored at ambient temperature $\left(\sim 21^{\circ} \mathrm{C}\right)$ and relative humidity $(\sim 50 \%)$. Sealing the samples prevented additional exposure to light and moisture.

STXM analysis was performed continuously from 2010 to 2015 at Lawrence Berkeley National Laboratory's (LBNL) Advanced Light Source (ALS) at beamline 5.3.2.2 described in detail elsewhere (Kilcoyne et al., 2003). The STXM instrument provides raw images with photon counts representing pixel intensities. The pixel intensities are converted to optical density (OD) by the relation $\ln \frac{I}{I_{0}}=-\mu \rho t$ where $I_{0}$ and I are the photon counts for particle-free and particlecontaining regions of the image, respectively, $\mu$ is the mass absorption coefficient, $\rho$ is the material density, and $t$ is the particle thickness. MATLAB algorithms described originally in an earlier publication (Moffet et al., 2010) were used to identify the regions of an aerosol containing $\mathrm{BC}$, organic carbon, and inorganic species. However, the mapping algorithms implemented here utilized only four images at different photon energies. Mapping with four images decreases analysis time, allowing for higher throughput and, thus, anal- ysis of a larger population of particles. To generate a carbon based map, aerosol particles were imaged at $278 \mathrm{eV}$ (the carbon pre-edge), $285.4 \mathrm{eV}\left(\mathrm{sp}^{2} \mathrm{C}^{*}=\mathrm{C}\right), 288.6 \mathrm{eV}\left(\mathrm{C}^{*} \mathrm{OOH}\right)$, and $320 \mathrm{eV}$ (the carbon post-edge). Characteristic single energy images at these energies are shown in Fig. 1a-d. Typically, at each energy, a $15 \times 15 \mu^{2}$ image was acquired with $0.035 \mu \mathrm{m}$ pixel size and $1 \mathrm{~ms}$ dwell time. Occasionally, $\sim 120$ different constant energy images were utilized in this study to obtain a high-resolution carbon spectrum. For consistency, the same set of four constant energy images was used to classify particles in spectral images acquired containing both 120 and 4 energy points.

Maps derived from these four images are shown in Fig. 1e-g. To map "organic" regions, the difference between the carboxylic transition $\left(\mathrm{C}^{*} \mathrm{OOH}, 288.6 \mathrm{eV}\right)$ and the preedge of carbon is used and the resulting map is shown in Fig. 1e. The inorganic map, representing non-carbonaceous inorganic dominant regions, is derived from the ratio of the pre-edge $(278 \mathrm{eV})$ to the post-edge $(320 \mathrm{eV})$ ratio $\left(\mathrm{OD}_{\text {pre }} / \mathrm{OD}_{\text {post }}\right)$ and is shown in Fig. 1f. Non-carbonaceous, inorganic inclusions of $\left(\mathrm{NH}_{4}\right)_{2} \mathrm{SO}_{4}$ and $\mathrm{NaCl}$ were confirmed using energy dispersive X-ray spectroscopy for these CARES samples (Moffet et al., 2013). BC is mapped by normalizing the $\mathrm{C}^{*}=\mathrm{C} \mathrm{sp}{ }^{2}$ hybridized carbon peak at $285.4 \mathrm{eV}$ to the post-edge absorbance at $320 \mathrm{eV}$. This ratio is then scaled with respect to highly oriented pyrolitic graphite (HOPG) enabling calculation of the $\mathrm{sp}^{2}$ hybridization fraction (Hopkins et al., 2007):

$\% \mathrm{sp}^{2}=\frac{\mathrm{OD}(285.4 \mathrm{eV})}{\mathrm{OD}(320)} \times \frac{\mathrm{OD}(320)_{\mathrm{HOPG}}}{\mathrm{OD}(285.4)_{\mathrm{HOPG}}}$.

BC particles, which mostly consist of elemental carbon, are expected to have a high $\% \mathrm{sp}^{2}$ and appear as bright areas in Fig. 1g. This paper focuses on quantifying the morphology of particles containing these high $\% \mathrm{sp}^{2}$ regions which are defined as BC.

To define organic carbon rich (OC), inorganic noncarbonaceous rich (IN), and black carbon (BC) regions, thresholds for each of the three maps in Fig. 1e-g were set using the following criteria: (1) pixels at $288.6 \mathrm{eV}$ with intensities 3 times below the signal to noise ratio were set to zero; (2) pixels having $\mathrm{OD}_{\text {pre }} / \mathrm{OD}_{\text {post }}<0.5$ were set to zero as discussed in Moffet et al. (2010); and (3) the $\% \mathrm{sp}^{2}$ was set to zero below a value of $35 \%$. The empirical determination of the threshold value of $35 \%$ is discussed elsewhere (Moffet et al., 2011). Areas of each of the maps with fewer than 7 conjoined pixels were excluded. Thresholds for maps in Fig. 1e-g were applied to produce binary images. In Fig. 1h, to highlight the $\mathrm{BC}$ mixing state, these three binary images are overlaid in the following order: organic, inorganic, $\mathrm{sp}^{2}$.

Morphological information for the compositional regions of interest (inclusion center of mass, convexity, area) was obtained using the MATLAB image processing toolbox and other custom-written algorithms. Particles not completely captured by the image were not included in the analysis. In- 


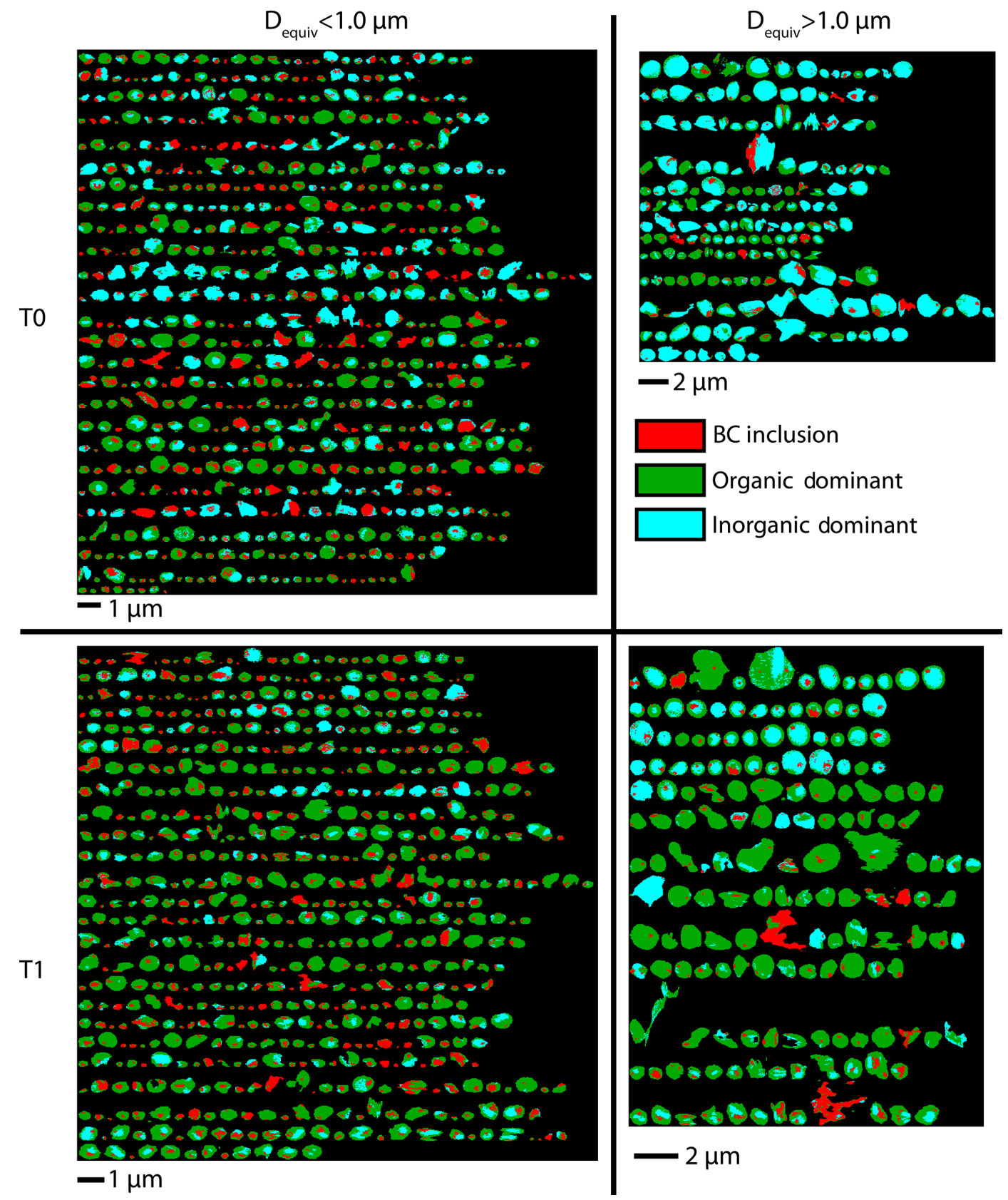

Figure 2. Cropped composition maps for all BC containing particles identified in CARES samples collected at T0 (top) and T1 (bottom). The submicron (left panels) particles are separated from the supermicron particles (right panels).

dividual particle maps were cropped and stored for interactive and query based plotting. Interactive single particle maps were utilized for quality control of the data and to exclude particles that were misidentified as BC. For the interactive visualization, all of the particles within a user-defined subset are displayed. Individual particles are selected via a graphical user interface. Upon selection, the raw data for that particular data set are activated to allow further scrutiny of the data. Occasionally, visual inspection indicated particles may have been misclassified. These particles were omitted from the analysis. Specific biological particle types were identified erroneously as BC and were excluded from the data set based on their morphology and/or spectral characteristics. Additionally, small nominally pure $\mathrm{BC}$ particles were occasionally unidentified due to the specifics of the initial particle detection methods. Another problem area for the identification of $\mathrm{BC}$ particles is regions close to inorganic inclusions due to high background levels caused by non-carbonaceous species. MATLAB routines packaged as an application are available 


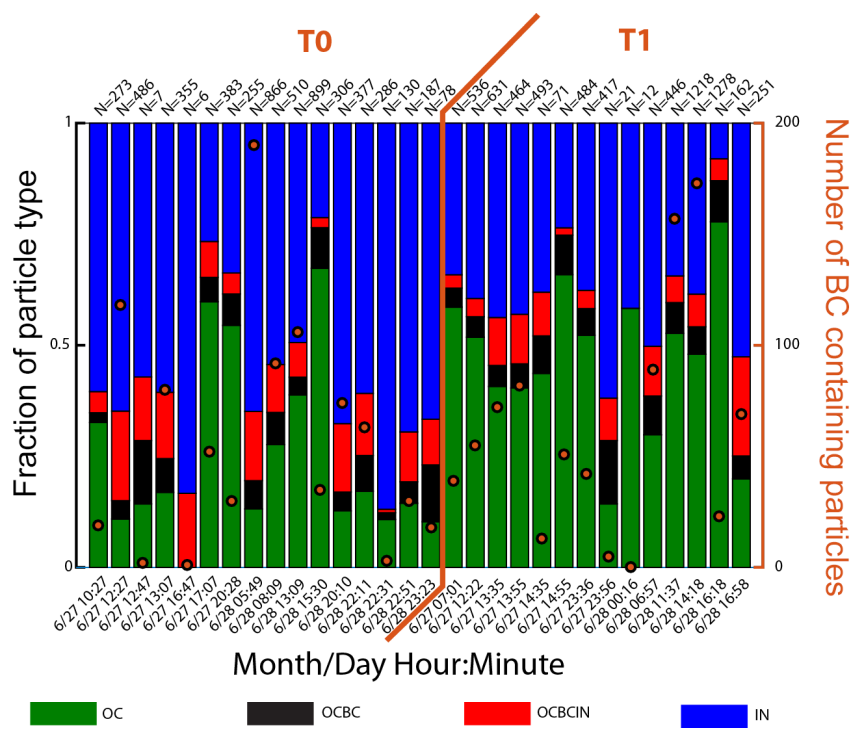

Figure 3. Summary of all particles analyzed from the CARES STXM data set. Green bars represent particles only containing the OC rich phase, black bars indicate particles containing BC and OC, red indicates the fraction of particles containing $\mathrm{OC}, \mathrm{BC}$, and $\mathrm{IN}$, and blue bars indicate the fraction of particles containing an inorganic dominant phase (IN). Orange dots indicate the total number of BC particles analyzed from a particular sample. The total number $(N)$ of particles analyzed in each sample is indicated on the top of the figure.

at https://www.mathworks.com/matlabcentral/fileexchange/ 58259-stxm-particleanalysis2-gui.

\section{Results}

\subsection{BC mixing state}

$\mathrm{X}$-ray spectromicroscopy is one of the few techniques that use chemical markers for imaging the internal structures of BC containing particles. Figure 1 shows a typical field of view for samples collected during the CARES campaign. The BC map in Fig. 1g and h demonstrates a variety of BC morphology including large, fractal particles, large compact particles, and small compact particles. BC particles were internally mixed with inorganic and organic material. For example, the large fractal BC particle (particle 1, Fig. 1g and h) has a small compact inorganic inclusion on its upper extremity and is surrounded by organic carbon. Other BC containing particles have small compact $\mathrm{BC}$ inclusions located towards the center of the particle (particles 3 and 4). Some of the small $\mathrm{BC}$ inclusions are surrounded by mostly organic material (particle 4), whereas other small compact BC particles are surrounded by inorganic materials (particles 5 and 6 ). The organic map shown in Fig. 1e demonstrates that there are organic coatings surrounding most of the particles. Furthermore, the branched $\mathrm{BC}$ particle shows considerable intensity in the organic $\left(\mathrm{C}^{*} \mathrm{OOH}\right)$. The magnitude of the ratio of the pre-edge to the post-edge is proportional to the total mass of non-carbonaceous inorganic species. Inorganic inclusions appear as regions of high intensity in Fig. If or blue areas in Fig. 1h. Sea salt particles are common in the region and, based on their cubic morphology, the larger particles containing inorganic regions are likely sea salt. Smaller particles having inorganic dominant regions likely contain sulfate (Moffet et al., 2013).

Based on these maps, the mixing state of the particles was stored in a database for the subsequent analysis of BC morphology. The label based mixing state is defined from particles having $\mathrm{OC}, \mathrm{BC}$, or IN regions defined by the binary maps shown in Fig. 1h. For example, if a particle contains both organic and black carbon regions it is labeled OCBC and so on. Figure 2 shows cropped single particle maps for all BC particles utilized in this study separated by the sampling site and size (submicron and supermicron). The most striking difference between $\mathrm{BC}$ particles from $\mathrm{T} 0$ and $\mathrm{T} 1$ is the high number of inorganic dominant regions for $\mathrm{T} 0$ particles. T0 was impacted by sea spray and sulfates from petroleum refineries located in the San Francisco Bay Area (Laskin et al., 2012). The large inorganic dominant particles can be attributed to sea spray particles that have coagulated with $\mathrm{BC}$ emissions from the Bay Area. Many of the smaller inorganic dominant particles are likely agglomerates of $\mathrm{BC}$ and sulfates. Indeed, many of the inorganic regions for submicron particles have elongated inorganic regions which are consistent with the crystalline structure of ammonium sulfate (Li et al., 2003). Frequently, BC inclusions were seen on the outside edge of an inorganic dominant region; this arrangement may have occurred upon efflorescence, when a salt excludes the aqueous phase (Liu et al., 2008). At T1, the majority of the $\mathrm{BC}$ containing particles included a larger fraction of organic dominant regions as a result of the increased photochemical age and large availability of secondary organic aerosol precursors in the foothills of the Sierra Nevada (Moffet et al., 2013).

A small portion of particles contained more than a single $\mathrm{BC}$ inclusion. In some cases, the identification of more than one $\mathrm{BC}$ inclusion was determined to be an artifact of the automated analysis used in the identification of the $\mathrm{BC}$ inclusions. However, in many cases, larger particles tend to be associated with more than one BC inclusion per particle, as confirmed manually with an interactive version of Fig. 2 . Few studies have examined the radiative effects of particles containing multiple BC inclusions. Others (Jacobson, 2006) have commented that as hydrometeors (cloud and precipitation particles) evaporate, the non-volatile $\mathrm{BC}$ inclusions coalesce. While submicron aerosol may not be necessarily identical to hydrometers discussed in that study, it is expected that the behavior upon evaporation will be similar. Here, some particle images show that the $\mathrm{BC}$ inclusions are separated by inorganic (presumably crystalline) dominant regions. 


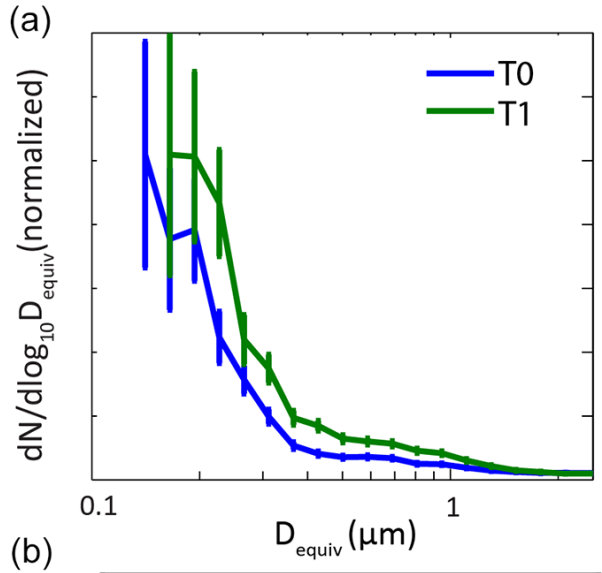

(b)

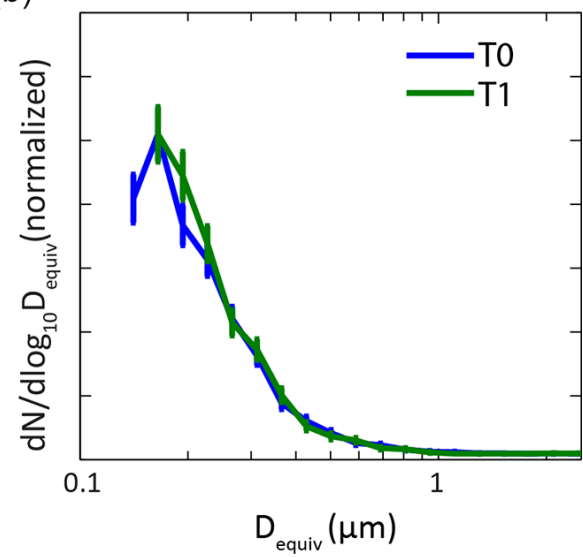

Figure 4. (a) Size distribution of $\mathrm{BC}$ containing particles at $\mathrm{T} 0$ (blue) and T1 (green). (b) Size distribution of BC inclusions at T0 (blue) and T1 (green).

For the entire particle population, particle mixing states and the fraction of $\mathrm{BC}$ particles were characterized for each sampling time as indicated in Fig. 3. Figure 3 shows the number of particles analyzed and the fraction of those particles with a particular mixing state. Based on the individual particle maps, OCBC and OCBCIN particles were distinguished from OC and INOC particle types. Overall, the major difference between $\mathrm{T} 0$ and $\mathrm{T} 1$ is the larger abundance of nominally pure homogenous organic particles at T1. As seen in Fig. 2, $\mathrm{BC}$ particles at $\mathrm{T} 1$ are more frequently mixed with the $\mathrm{OC}$ phase rather than with the IN phase. Generally, as the number of nominally pure OC particles increased, the OCBC particle type increased $\left(r=+0.50, r^{2}=0.25\right)$. Additionally, as the IN particle type increased, the OCBCIN particle type increased $\left(r=+0.79, r^{2}=0.62\right)$. As can be qualitatively seen in Fig. 2, most of the carbon mass likely comes from the particle $\mathrm{BC}$ component. This observation is supported by the mass based carbonaceous mixing state of a smaller subset of these data parameterized using mass based entropy metrics (O'Brien et al., 2015; Riemer and West, 2013). In O'Brien et al. (2015), entropy metrics were used to calculate a diversity that represents the effective number of species per par-

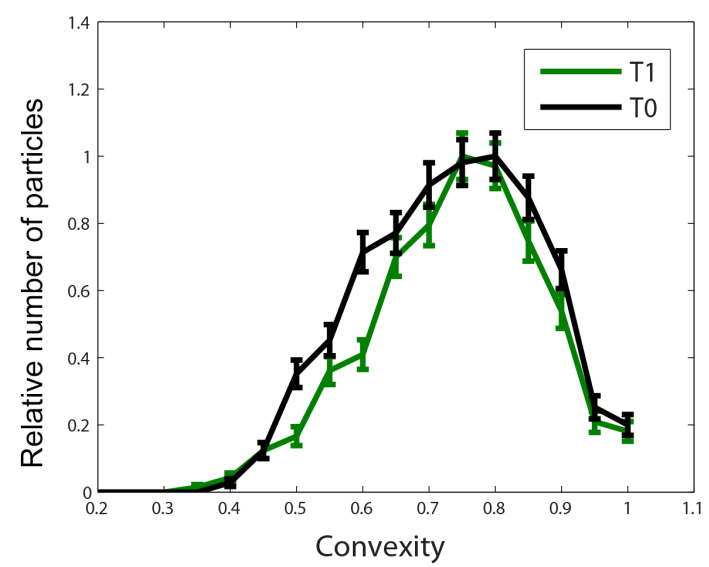

Figure 5. Histograms of BC inclusion convexity for the T0 and T1 sites.

ticle or in the bulk population. In this case diversities were specified using the OC, BC, and IN components such that a particle or population can have a maximum diversity of 3 . Generally, due to the dense nature of the $\mathrm{BC}$, emission of $\mathrm{BC}$ particles controls trends in the overall mass based carbonaceous mixing state. Given that the average individual particle diversity did not increase with the bulk population diversity, the $\mathrm{BC}$ containing particles are considered to be externally mixed with respect to the carbonaceous mixing state defined using STXM measurements (O'Brien et al., 2015). Nevertheless, the majority of $\mathrm{BC}$ containing particles are associated with other species. Because the size and morphological characteristics of the OC and IN phases within the BC particles are expected to impact the optical properties of the particles, those properties are quantified here.

\subsection{Size and shape characteristics}

For internally mixed BC particles, both the size of the BC inclusion and the overall size of particle have the greatest influence on the light extinction (Moffet and Prather, 2009). Most importantly, the absorption cross section is driven largely by the size of the $\mathrm{BC}$ inclusion. To provide a best estimate of the $\mathrm{BC}$ inclusion size distribution and overall particle size distributions, the identified $\mathrm{BC}$ areas were used to calculate a circular equivalent diameter $\left(D_{\text {eqiv }}=2 \sqrt{\frac{A_{\text {roi }}}{\pi}}\right)$, where $A_{\text {roi }}$ is the area of the region of interest (ROI) identified by the mapping described above. Figure 4a shows the total host particle size characteristics of $\mathrm{BC}$ containing particles sampled at $\mathrm{T} 0$ and $\mathrm{T} 1$ scaled by the transmission efficiency of the impactor (see Supplement). These characteristics are similar, but there are small differences that may be due to particle aging. Compared to $\mathrm{T} 0$, the total particle distribution for $\mathrm{T} 1$ shows a significantly higher population of larger particles. This result is expected considering that the $\mathrm{T} 0$ site is located in a source region for freshly emitted BC particles. Due to growth by condensation of organic material, larger particle sizes are also 
(a)
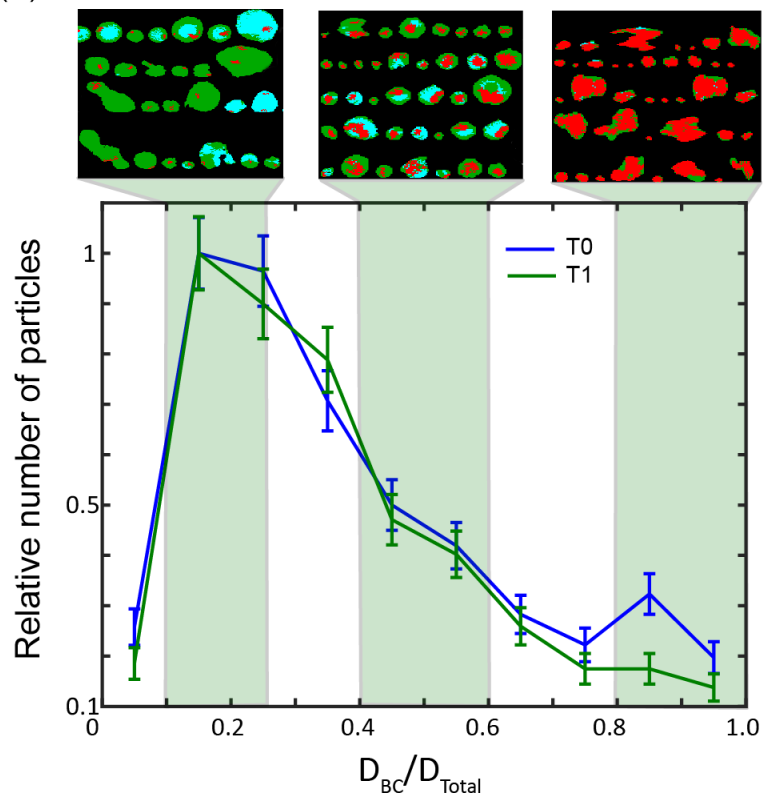

(b)

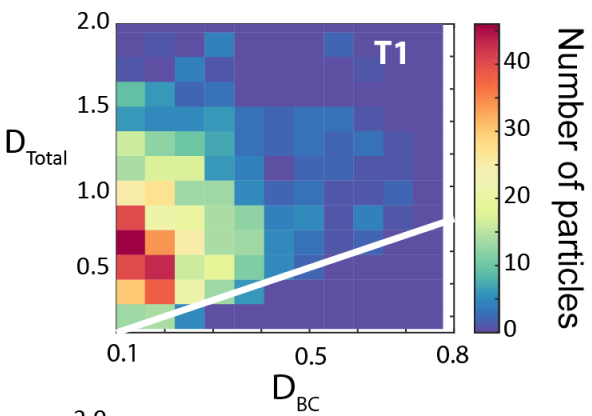

(c)

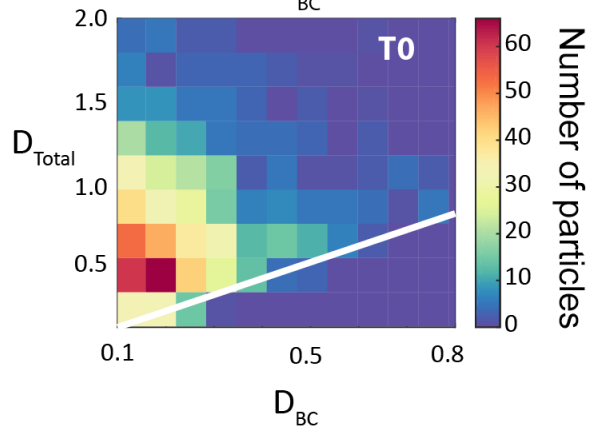

Figure 6. (a) Distributions of the ratio of the $\mathrm{BC}$ inclusion diameter to the total particle diameter $\left(D_{\mathrm{BC}} / D_{\text {total }}\right)$ after transmission efficiency correction. Images shown above the plot are examples of particles having (from left to right) $0.1<D_{\mathrm{BC}} / D_{\text {total }}<0.25$, $0.4<D_{\mathrm{BC}} / D_{\text {total }}<0.6$, and $0.8<D_{\mathrm{BC}} / D_{\text {total }}<1.0$. (b, c) Two-dimensional histograms showing the number of particles having a total diameter $D_{\text {total }}$ and a BC core diameter $D_{\mathrm{BC}}$ for T0 (c) and T1 (b). White lines indicate $1: 1$ ratios.

expected at T1. Distributions from both sites show enhanced numbers in the droplet mode $(\sim 200-1000 \mathrm{~nm})$. The transmission efficiency curve shown in Fig. S1 in the Supplement systematically overestimates the transmission for particles below $300 \mathrm{~nm}$. Size distributions obtained using a scanning mobility particle sizer show much higher populations below $\sim 100 \mathrm{~nm}$, falling off more sharply than the total particle size distributions obtained here (Zaveri et al., 2012). Nevertheless, the influence of coating on the particles is apparent; we attribute the coating to the condensation of organic material on $\mathrm{BC}$ particles at the $\mathrm{T} 1$ site where particles are expected to be more aged.

The single scattering albedo of $\mathrm{BC}$ particles is highly sensitive to the size of the BC inclusion (Moffet and Prather, 2009). The fact that $\mathrm{BC}$ inclusion sizes at $\mathrm{T} 0$ and $\mathrm{T} 1$ are similar with only minor differences (Fig. 4b) suggests that restructuring of the particles to more compact shapes upon transport is negligible. Previous studies have implied that as BC particles age, the morphology changes from a branched, fractal morphology to a more compact morphology (Mikhailov et al., 2006; Huang et al., 1994; Ramachandran and Reist, 1995; Weingartner et al., 1997; Martins et al., 1998). As the freshly emitted fractal particles absorb liquid water due to the presence of hygroscopic species and become coated with organic material, capillary forces act to collapse the chain-like fractal particles. It is probable that most of the particles sampled during CARES are substantially aged and/or that the aging time (and subsequent col- lapse into compact shapes) is rapid. To quantify the extent of particle compaction between T0 and T1, particle convexity (convexity $=\frac{A}{A_{\mathrm{C} \text { vxHull }}}$, where $A_{\mathrm{CvxHull}}$ is the area of the convex hull around the particle area A) was calculated for the BC inclusions and is shown in Fig. 5. Convexity distributions for inclusions from $\mathrm{T} 0$ and $\mathrm{T} 1$ are similar, with the exception of a slightly higher number of inclusions with lower convexities at T0. Inclusions that are more branched have lower values of convexity (Coz and Leck, 2011); hence, the presence of more particles with lower convexities is consistent with the presence of fresh emissions at T0. It is possible that the resolution of the STXM instrument limits the ability to identify small $(<100 \mathrm{~nm})$ branched/fractal inclusions. However, even freshly emitted diesel soot particles become more compact at smaller sizes (Park et al., 2004). Moreover, monomer size tends to be around $40 \mathrm{~nm}$, which should be detectable by the STXM instrument. The monomers of BC aggregates are typically connected in order to form a branched, fractal particle, resulting in the observation that only larger particles have a high fractal dimension. Nevertheless, comparison of the convexity distributions between $\mathrm{T} 0$ and $\mathrm{T} 1$ indicates a small statistically significant population of less compact particles at T0 consistent with fresh emissions. However, it should be emphasized that the majority of particles at both sites have compact shapes and are likely due to the prevalence of aged $\mathrm{BC}$ containing particles.

To compare the distribution of coating thicknesses at $\mathrm{T} 0$ and $\mathrm{T} 1$, the ratio of the $\mathrm{BC}$ core diameter $\left(D_{\mathrm{BC}}\right)$ to the total 
particle diameter ( $\left.D_{\text {Total }}\right)$ was binned, scaled by the transmission efficiency, and displayed in Fig. 6a. Particles with thin coatings have $D_{\mathrm{BC}} / D_{\text {Total }}$ approaching 1, whereas particles with thick coatings have $D_{\mathrm{BC}} / D_{\text {Total }}$ approaching 0 . The T0 site shows a slightly enhanced mode of thinly coated particles compared to $\mathrm{T} 1$, indicating the presence of fresh $\mathrm{BC}$ emissions at the T0 site. This mode of thinly coated particles follows the $1: 1$ line in the two-dimensional histogram in Fig. 6c. In a separate study, Bond et al. analyzed the various regions of the $D_{\text {total }}$ vs. $D_{\mathrm{BC}}$ space (shown in Fig. $6 \mathrm{~b}-\mathrm{c}$ ) and found that particles that follow the $1: 1$ line are expected to have lower absorption amplifications compared to particles having thicker coatings (Bond et al., 2006). The majority of particles at both sites have thicker coatings; based on previous modeling studies these particles are expected to have larger absorption cross sections (Scarnato et al., 2013). As observed in other studies with stagnant regional air masses (Moffet and Prather, 2009; Moffet et al., 2008), these results highlight the predominance of particles with thick coatings in urban areas with similar meteorological conditions. For the CARES study, the source of these particles may be background transport from the neighboring industrial areas such as the San Francisco Bay Area.

\subsection{Location of $\mathrm{BC}$ inclusions within host particles}

The location of $\mathrm{BC}$ inclusions within the particle affects the optical properties of the particle (Fuller et al., 1999). A previous investigation associated with the CARES study found lower than expected absorption enhancements, possibly due to the location of the $\mathrm{BC}$ inclusions on the edge of the particles (Cappa et al., 2012). Figure 7 shows the distribution of locations of the $\mathrm{BC}$ inclusions within their host particle for $\mathrm{T} 0$ and $\mathrm{T} 1$. To enable comparison of particles between all sizes, the distance $\left(R_{\text {inc }}\right)$ of the $\mathrm{BC}$ inclusion center from the host particle center was normalized by the the longest distance $\left(R_{\max }\right)$ between the host particle center and the host particle edge (see the graphic illustration in Fig. 7). In this case, a ratio of $R_{\text {inc }} / R_{\max }=1$ corresponds to the longest distance of the BC inclusion from the particle center. Analysis of particles from two sampling sites showed minor differences in the locations of the $\mathrm{BC}$ inclusions within host particles, suggesting that the distribution of $\mathrm{BC}$ inclusions does not vary substantially between the urban (T0) and rural (T1) sampling sites. Slightly more BC inclusions are found closer to the edge of the host at T0. This is likely due to the higher frequency of inorganic inclusions at T0; the crystalline inorganic phase is thought to push the $\mathrm{BC}$ inclusions away from the center upon efflorescence. Moreover, BC particles may more easily mix with the $\mathrm{OC}$ phase when the particle is in the dry state. The bottom panel of Fig. 7 demonstrates that particles containing inorganic rich phases (OCBCIN particles) have an enhanced number of particles with the $\mathrm{BC}$ inclusion near the edge of the host; this trend is enhanced when particles with large $(500 \mathrm{~nm})$ inorganic inclusions are considered.
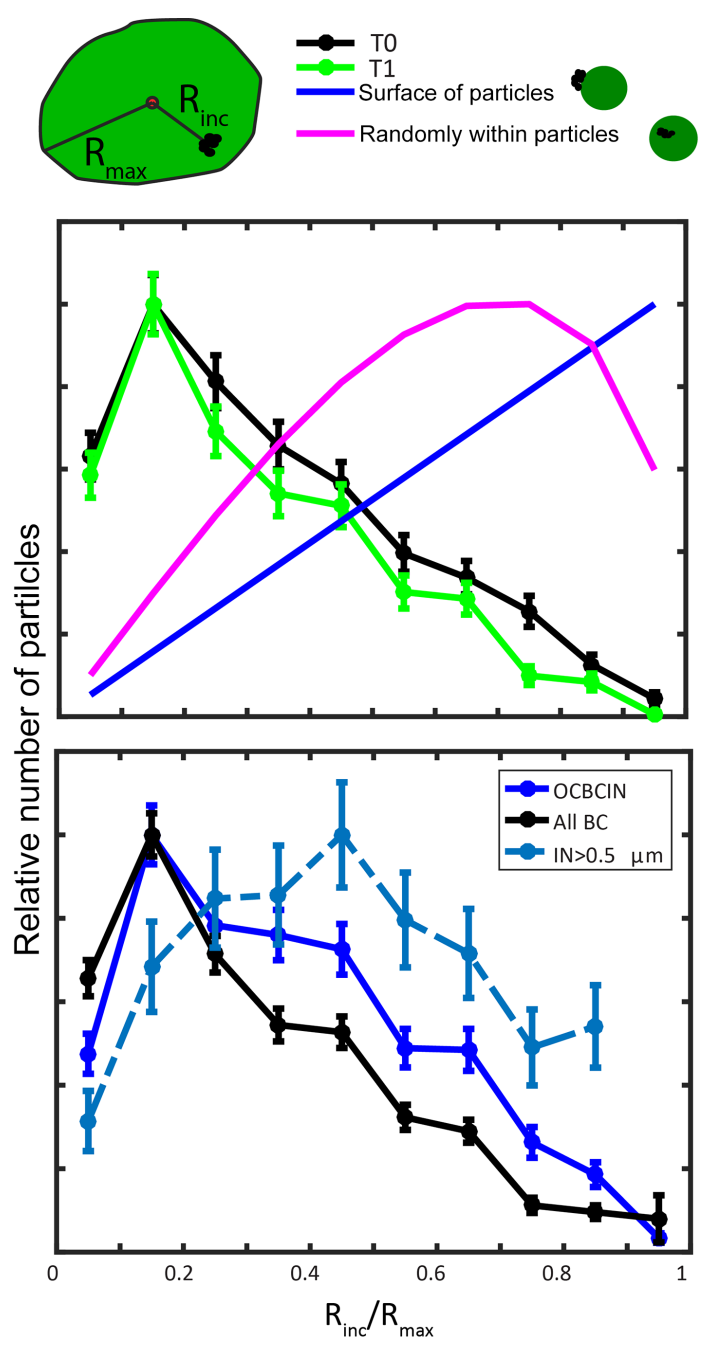

Figure 7. (Top) Distance of the BC inclusions from the center to the host particle for the CARES field study at the T0 (black) or T1 (green) sites. The distance of the $\mathrm{BC}$ inclusion $\left(R_{\mathrm{inc}}\right)$ is normalized to the distance from the particle center of mass to the farthest edge $\left(R_{\max }\right)$ (see illustration above plot). Modeled locations of BC inclusions are shown assuming the inclusion was on the surface (blue) or randomly within the host particle (magenta) before impaction. (Bottom) Distance of BC inclusion from the host center for all BC containing particles (black), OCBCIN particles, and particles containing inorganic inclusions (IN) having a geometric diameter larger than $500 \mathrm{~nm}$.

These results demonstrate that the majority of the $\mathrm{BC}$ inclusions were found in the center of their impacted host particle at both sites and that the presence of inorganic dominant inclusions acts to push the $\mathrm{BC}$ inclusion farther from the center of the host.

Of note, interpreting Fig. 7 may be biased because the distribution depends on the orientation of the $\mathrm{BC}$ inclusion shortly before impaction. For example, a BC inclusion can be attached to the outside of the host particle at its lowest vertical coordinate (the bottom of the host). When impacted, 
the two-dimensional image of the particle with the $\mathrm{BC}$ inclusion would appear to be at the center even though it was attached to the outside of the host particle. To explain the distributions in Fig. 7 with respect to $\mathrm{BC}$ inclusion orientation, a model was constructed where the $\mathrm{BC}$ inclusion is positioned on or within spherical host (see the supplementary section). From this model, calculated distributions of the BC inclusion location were derived assuming the particle was randomly distributed either on the surface or within the volume of the host. Figure 7 demonstrates that the $\mathrm{BC}$ inclusions are preferentially located at the host center compared to the modeled distributions. Figure S3 demonstrates that if we change $R_{\max }$ to be the radius of the largest circle inscribing the host particle, the BC inclusions measured near the center are still enhanced compared to the modeled distributions in Fig. 7. The modeled distributions may underpredict the number of BC inclusions in the center of the impacted host particle because (1) the BC inclusion is "pinned" to the surface, while the host particle material spreads away from it, or (2) the BC inclusion is preferentially located at the host particle center due to the condensation of organic and inorganic material around the host particle in the atmosphere. To address point 1 , a more detailed model of the particle impaction process is required. Specifically, the phase of the organic and inorganic material must be considered. If the inorganic/organic phase of the particles is liquid, it is possible that the impaction process can be modeled using computational fluid dynamics. However, there has recently been a body of research indicating that the organic material that frequently hosts $\mathrm{BC}$ inclusions may have a high viscosity and thus resist spreading (Booth et al., 2014; O'Brien et al., 2014). Based on the analysis presented here, overall our data support a coating model where the centrally located BC inclusion is covered by non-absorbing material. Such coated BC inclusions will have higher absorption than particles that are on the surface of the non-absorbing host.

\section{Conclusions}

The statistical analysis presented here represents the state of BC containing particles at source (T0) and receptor (T1) sites in the California Central Valley during a period of high photochemical activity and pollution buildup. During this period, the overall particle size at the receptor site was significantly larger due to the condensation of organic and inorganic species. The BC inclusion sizes between the T0 and $\mathrm{T} 1$ sites showed no detectable differences. The absorption efficiency of $\mathrm{BC}$ containing particles is strongly dependent on the size of the BC inclusions. Hence, measurements such as these in other geographical locations are important to understand the radiative impact of particles.

The extent of coating on individual particles was quantified by calculating the ratios of the BC inclusion area equivalent diameter to the host area equivalent diameter. The T0 site had a small population of thinly coated particles compared to the $\mathrm{T} 1$ site. This is consistent with slightly smaller overall particle sizes at $\mathrm{T} 0$ and the assumption that $\mathrm{BC}$ at the source site (T0) should have thinner coatings due to the presence of fresh $\mathrm{BC}$ emissions. The majority of the $\mathrm{BC}$ containing particles at both sites had thick coatings indicative of aged background particles. The high abundance of aged particles is consistent with the stagnant pollution plume present over the sampling site during this period. To model radiative transfer in aged urban pollution, particle-resolved measurements, such as those presented in this study, are valuable for characterization of the morphological properties and relative populations of aged vs. fresh emissions.

Previous particle resolved measurements of BC containing particles from the CARES campaign have highlighted the effects of $\mathrm{BC}$ inclusion/host geometry on absorption. Here, the location of the $\mathrm{BC}$ inclusions within the particles attached to the substrate was characterized. Using a model of particle impaction, it was shown that the BC inclusions were not all located at the center, nor were they all likely to be located on the surface of the particle prior to impaction. Particles containing inorganic rich inclusions were more likely to have the $\mathrm{BC}$ inclusion pushed towards the edge of the host. To improve our understanding of the location of the $\mathrm{BC}$ inclusion within the impacted particle, more accurate models of particle impaction and spreading are needed in future studies.

\section{Data availability}

The data for this article are available upon request to the corresponding author.

\section{The Supplement related to this article is available online at doi:10.5194/acp-16-14515-2016-supplement.}

Acknowledgements. Funding for sample collection during the CARES study was provided by the Atmospheric Radiation Measurement Program sponsored by the US Department of Energy (DOE), Office of Science, Office of Biological and Environmental Research (OBER), Climate and Environmental Sciences Division (CESD). Funding for the data analysis was provided by the US DOE's Atmospheric System Research Program, BER under grants DE-SC0008643 and DE-SC0008613. The STXM/NEXAFS particle analysis was performed at beamlines 11.0.2 and 5.3.2 at the Advanced Light Source (ALS) at Lawrence Berkeley National Laboratory. The work at the ALS was supported by the Director, Office of Science, Office of Basic Energy Sciences, of the US DOE under contract DE-AC02-05CH11231. We thank A. L. D. Kilcoyne and T. Tyliszczak for their assistance with STXM experiments.

Edited by: R. Sullivan

Reviewed by: two anonymous referees 


\section{References}

Ackerman, T. P. and Toon, O. B.: Absorption of Visible Radiation in Atmosphere Containing Mixtures of Absorbing and NonAbsorbing Particles, Appl. Opt., 20, 3661-3668, 1981.

Adachi, K., Chung, S. H., Friedrich, H., and Buseck, P. R.: Fractal parameters of individual soot particles determined using electron tomography: Implications for optical properties, J. Geophys. Res.-Atmos., 112, D14202, doi:10.1029/2006jd008296, 2007.

Adachi, K. and Buseck, P. R.: Internally mixed soot, sulfates, and organic matter in aerosol particles from Mexico City, Atmos. Chem. Phys., 8, 6469-6481, doi:10.5194/acp-8-6469-2008, 2008.

Bond, T. C., Habib, G., and Bergstrom, R. W.: Limitations in the enhancement of visible light absorption due to mixing state, J. Geophys. Res.-Atmos., 111, D20211, doi:10.1029/2006JD007315, 2006.

Bond, T. C., Doherty, S. J., Fahey, D. W., Forster, P. M., Berntsen, T., DeAngelo, B. J., Flanner, M. G., Ghan, S., Karcher, B., Koch, D., Kinne, S., Kondo, Y., Quinn, P. K., Sarofim, M. C., Schultz, M. G., Schulz, M., Venkataraman, C., Zhang, H., Zhang, S., Bellouin, N., Guttikunda, S. K., Hopke, P. K., Jacobson, M. Z., Kaiser, J. W., Klimont, Z., Lohmann, U., Schwarz, J. P., Shindell, D., Storelvmo, T., Warren, S. G., and Zender, C. S.: Bounding the role of black carbon in the climate system: A scientific assessment, J. Geophys. Res.-Atmos., 118, 5380-5552, doi:10.1002/Jgrd.50171, 2013.

Booth, A. M., Murphy, B., Riipinen, I., Percival, C. J., and Topping, D. O.: Connecting Bulk Viscosity Measurements to Kinetic Limitations on Attaining Equilibrium for a Model Aerosol Composition, Environ. Sci. Technol., 48, 9298-9305, doi:10.1021/Es501705c, 2014.

Cahill, J. F., Suski, K., Seinfeld, J. H., Zaveri, R. A., and Prather, K. A.: The mixing state of carbonaceous aerosol particles in northern and southern California measured during CARES and CalNex 2010, Atmos. Chem. Phys., 12, 10989-11002, doi:10.5194/acp-12-10989-2012, 2012.

Cappa, C. D., Onasch, T. B., Massoli, P., Worsnop, D. R., Bates, T. S., Cross, E. S., Davidovits, P., Hakala, J., Hayden, K. L., Jobson, B. T., Kolesar, K. R., Lack, D. A., Lerner, B. M., Li, S. M., Mellon, D., Nuaaman, I., Olfert, J. S., Petaja, T., Quinn, P. K., Song, C., Subramanian, R., Williams, E. J., and Zaveri, R. A.: Radiative Absorption Enhancements Due to the Mixing State of Atmospheric Black Carbon, Science, 337, 1078-1081, doi:10.1126/science.1223447, 2012.

Cazorla, A., Bahadur, R., Suski, K. J., Cahill, J. F., Chand, D., Schmid, B., Ramanathan, V., and Prather, K. A.: Relating aerosol absorption due to soot, organic carbon, and dust to emission sources determined from in-situ chemical measurements, Atmos. Chem. Phys., 13, 9337-9350, doi:10.5194/acp-13-9337-2013, 2013.

Chakrabarty, R. K., Beres, N. D., Moosmuller, H., China, S., Mazzoleni, C., Dubey, M. K., Liu, L., and Mishchenko, M. I.: Soot superaggregates from flaming wildfires and their direct radiative forcing, Sci. Rep.-UK, 4, 5508, doi:10.1038/Srep05508, 2014.

China, S., Mazzoleni, C., Gorkowski, K., Aiken, A. C., and Dubey, M. K.: Morphology and mixing state of individual freshly emitted wildfire carbonaceous particles, Nat. Commun., 4, 2122, doi:10.1038/Ncomms3122, 2013.
Coz, E. and Leck, C.: Morphology and state of mixture of atmospheric soot aggregates during the winter season over Southern Asia-a quantitative approach, Tellus B, 63, 107-116, doi:10.1111/j.1600-0889.2010.00513.x, 2011.

Fast, J. D., Gustafson Jr., W. I., Berg, L. K., Shaw, W. J., Pekour, M., Shrivastava, M., Barnard, J. C., Ferrare, R. A., Hostetler, C. A., Hair, J. A., Erickson, M., Jobson, B. T., Flowers, B., Dubey, M. K., Springston, S., Pierce, R. B., Dolislager, L., Pederson, J., and Zaveri, R. A.: Transport and mixing patterns over Central California during the carbonaceous aerosol and radiative effects study (CARES), Atmos. Chem. Phys., 12, 1759-1783, doi:10.5194/acp-12-1759-2012, 2012.

Fast, J. D., Allan, J., Bahreini, R., Craven, J., Emmons, L., Ferrare, R., Hayes, P. L., Hodzic, A., Holloway, J., Hostetler, C., Jimenez, J. L., Jonsson, H., Liu, S., Liu, Y., Metcalf, A., Middlebrook, A., Nowak, J., Pekour, M., Perring, A., Russell, L., Sedlacek, A., Seinfeld, J., Setyan, A., Shilling, J., Shrivastava, M., Springston, S., Song, C., Subramanian, R., Taylor, J. W., Vinoj, V., Yang, Q., Zaveri, R. A., and Zhang, Q.: Modeling regional aerosol and aerosol precursor variability over California and its sensitivity to emissions and long-range transport during the $2010 \mathrm{CalNex}$ and CARES campaigns, Atmos. Chem. Phys., 14, 10013-10060, doi:10.5194/acp-14-10013-2014, 2014.

Fuller, K. A., Malm, W. C., and Kreidenweis, S. M.: Effects of mixing on extinction by carbonaceous particles, J. Geophys. Res.Atmos., 104, 15941-15954, 1999.

Hopkins, R. J., Tivanski, A. V., Marten, B. D., and Gilles, M. K.: Chemical bonding and structure of black carbon reference materials and individual carbonaceous atmospheric aerosols, J. Aerosol. Sci., 38, 573-591, doi:10.1016/j.jaerosci.2007.03.009, 2007.

Huang, P. F., Turpin, B. J., Pipho, M. J., Kittelson, D. B., and Mcmurry, P. H.: Effects of Water Condensation and Evaporation on Diesel Chain-Agglomerate Morphology, J. Aerosol. Sci., 25, 447-459, doi:10.1016/0021-8502(94)90063-9, 1994.

IPCC: Climate Change 2013: The Physical Science Basis, Cambridge, United Kingdom and New York, NY, USA, 996, 2013.

Jacobson, M. Z.: Strong radiative heating due to the mixing state of black carbon in atmospheric aerosols, Nature, 409, 695-697, 2001.

Jacobson, M. Z.: Effects of externally-through-internally-mixed soot inclusions within clouds and precipitation on global climate, J. Phys. Chem. A, 110, 6860-6873, doi:10.1021/jp056391r, 2006.

Kilcoyne, A. L. D., Tyliszczak, T., Steele, W. F., Fakra, S., Hitchcock, P., Franck, K., Anderson, E., Harteneck, B., Rightor, E. G., Mitchell, G. E., Hitchcock, A. P., Yang, L., Warwick, T., and Ade, H.: Interferometer-controlled scanning transmission X-ray microscopes at the Advanced Light Source, J. Synchrotron Radiat., 10, 125-136, 2003.

Knopf, D. A., Alpert, P. A., Wang, B., O’Brien, R. E., Kelly, S. T., Laskin, A., Gilles, M. K., and Moffet, R.: Microspectroscopic imaging and characterization of individually identified ice nucleating particles from a case field study, J. Geophys. Res.-Atmos., 119, 10365-10381, doi:10.1002/2014JD021866, 2014.

Laskin, A., Iedema, M. J., and Cowin, J. P.: Time-resolved aerosol collector for CCSEM/EDX single-particle analysis, Aerosol Sci. Technol., 37, 246-260, 2003. 
Laskin, A., Cowin, J. P., and Iedema, M. J.: Analysis of individual environmental particles using modern methods of electron microscopy and X-ray microanalysis, J. Electron. Spectrosc., 150, 260-274, 2006.

Laskin, A., Moffet, R. C., Gilles, M. K., Fast, J. D., Zaveri, R. A., Wang, B. B., Nigge, P., and Shutthanandan, J.: Tropospheric chemistry of internally mixed sea salt and organic particles: Surprising reactivity of $\mathrm{NaCl}$ with weak organic acids, J. Geophys. Res.-Atmos., 117, D15302, doi:10.1029/2012jd017743, 2012.

Li, J., Posfai, M., Hobbs, P. V., and Buseck, P. R.: Individual aerosol particles from biomass burning in southern Africa: 2, Compositions and aging of inorganic particles, J. Geophys. Res.-Atmos., 108, 8484, doi:10.1029/2002jd002310, 2003.

Liu, Y., Yang, Z., Desyaterik, Y., Gassman, P. L., Wang, H., and Laskin, A.: Hygroscopic behavior of substrate-deposited particles studied by micro-FT-IR spectroscopy and complementary methods of particle analysis, Anal. Chem., 80, 633-642, doi:10.1021/ac701638r, 2008.

Martins, J. V., Hobbs, P. V., Weiss, R. E., and Artaxo, P.: Sphericity and morphology of smoke particles from biomass burning in Brazil, J. Geophys. Res.-Atmos., 103, 32051-32057, doi:10.1029/98jd01153, 1998.

Mikhailov, E. F., Vlasenko, S. S., Podgorny, I. A., Ramanathan, V., and Corrigan, C. E.: Optical properties of soot-water drop agglomerates: An experimental study, J. Geophys. Res.-Atmos., 111, D07209, doi:10.1029/2005JD006389, 2006.

Moffet, R. C., Qin, X. Y., Rebotier, T., Furutani, H., and Prather, K. A.: Chemically segregated optical and microphysical properties of ambient aerosols measured in a single-particle mass spectrometer, J. Geophys. Res.-Atmos., 113, D12213, doi:10.1029/2007jd009393, 2008.

Moffet, R. C. and Prather, K. A.: In-situ measurements of the mixing state and optical properties of soot with implications for radiative forcing estimates, P. Natl. Acad. Sci. USA, 106, 1187211877, doi:10.1073/pnas.0900040106, 2009.

Moffet, R. C., Henn, T., Laskin, A., and Gilles, M. K.: Automated Chemical Analysis of Internally Mixed Aerosol Particles Using X-ray Spectromicroscopy at the Carbon K-Edge, Anal. Chem., 82, 7906-7914, 2010.

Moffet, R. C., Tivanski, A. V., and Gilles, M. K.: Scanning Transmission X-ray Microscopy: Applications in Atmosheric Aerosol Research, in: Fundamentals and Applications in Aerosol Spectroscopy, edited by: Signorell, R. and Reid, J. P., CRC Press, Boca Raton, 419 pp., 2011.

Moffet, R. C., Rödel, T. C., Kelly, S. T., Yu, X. Y., Carroll, G. T., Fast, J., Zaveri, R. A., Laskin, A., and Gilles, M. K.: Spectro-microscopic measurements of carbonaceous aerosol aging in Central California, Atmos. Chem. Phys., 13, 1044510459, doi:10.5194/acp-13-10445-2013, 2013.

O’Brien, R. E., Neu, A., Epstein, S. A., MacMillan, A. C., Wang, B. B., Kelly, S. T., Nizkorodov, S. A., Laskin, A., Moffet, R. C., and Gilles, M. K.: Physical properties of ambient and laboratorygenerated secondary organic aerosol, Geophys. Res. Lett., 41, 4347-4353, doi:10.1002/2014gl060219, 2014.

O'Brien, R. E., Wang, B. B., Laskin, A., Riemer, N., West, M., Zhang, Q., Sun, Y. L., Yu, X. Y., Alpert, P., Knopf, D. A., Gilles, M. K., and Moffet, R. C.: Chemical imaging of ambient aerosol particles: Observational constraints on mixing state parameterization, J. Geophys. Res.-Atmos., 120, 9591-9605, doi:10.1002/2015JD023480, 2015.

Park, K., Kittelson, D. B., and McMurry, P. H.: Structural properties of diesel exhaust particles measured by transmission electron microscopy (TEM): Relationships to particle mass and mobility, Aerosol Sci. Technol., 38, 881-889, doi:10.1080/027868290505189, 2004.

Ramachandran, G. and Reist, P. C.: Characterization of Morphological-Changes in Agglomerates Subject to Condensation and Evaporation Using Multiple Fractal Dimensions, Aerosol Sci. Technol., 23, 431-442, doi:10.1080/02786829508965326, 1995.

Ramanathan, V. and Feng, Y.: On avoiding dangerous anthropogenic interference with the climate system: Formidable challenges ahead, P. Natl. Acad. Sci. USA, 105, 14245-14250, doi:10.1073/pnas.0803838105, 2008.

Ramanathan, V. and $\mathrm{Xu}, \mathrm{Y}$. Y.: The Copenhagen Accord for limiting global warming: Criteria, constraints, and available avenues, P. Natl. Acad. Sci. USA, 107, 8055-8062, doi:10.1073/pnas.1002293107, 2010.

Riemer, N. and West, M.: Quantifying aerosol mixing state with entropy and diversity measures, Atmos. Chem. Phys., 13, 11423 11439, doi:10.5194/acp-13-11423-2013, 2013.

Rogelj, J., Schaeffer, M., Meinshausen, M., Shindell, D. T., Hare, W., Klimont, Z., Velders, G. J. M., Amann, M., and Schellnhuber, H. J.: Disentangling the effects of $\mathrm{CO}_{2}$ and short-lived climate forcer mitigation, P. Natl. Acad. Sci. USA, 111, 16325-16330, 10.1073/pnas.1415631111, 2014.

Scarnato, B. V., Vahidinia, S., Richard, D. T., and Kirchstetter, T. W.: Effects of internal mixing and aggregate morphology on optical properties of black carbon using a discrete dipole approximation model, Atmos. Chem. Phys., 13, 5089-5101, doi:10.5194/acp-13-5089-2013, 2013.

Weingartner, E., Burtscher, H., and Baltensperger, U.: Hygroscopic properties of carbon and diesel soot particles, Atmos. Environ., 31, 2311-2327, doi:10.1016/S1352-2310(97)00023-X, 1997.

Zaveri, R. A., Shaw, W. J., Cziczo, D. J., Schmid, B., Ferrare, R. A., Alexander, M. L., Alexandrov, M., Alvarez, R. J., Arnott, W. P., Atkinson, D. B., Baidar, S., Banta, R. M., Barnard, J. C., Beranek, J., Berg, L. K., Brechtel, F., Brewer, W. A., Cahill, J. F., Cairns, B., Cappa, C. D., Chand, D., China, S., Comstock, J. M., Dubey, M. K., Easter, R. C., Erickson, M. H., Fast, J. D., Floerchinger, C., Flowers, B. A., Fortner, E., Gaffney, J. S., Gilles, M. K., Gorkowski, K., Gustafson, W. I., Gyawali, M., Hair, J., Hardesty, R. M., Harworth, J. W., Herndon, S., Hiranuma, N., Hostetler, C., Hubbe, J. M., Jayne, J. T., Jeong, H., Jobson, B. T., Kassianov, E. I., Kleinman, L. I., Kluzek, C., Knighton, B., Kolesar, K. R., Kuang, C., Kubátová, A., Langford, A. O., Laskin, A., Laulainen, N., Marchbanks, R. D., Mazzoleni, C., Mei, F., Moffet, R. C., Nelson, D., Obland, M. D., Oetjen, H., Onasch, T. B., Ortega, I., Ottaviani, M., Pekour, M., Prather, K. A., Radney, J. G., Rogers, R. R., Sandberg, S. P., Sedlacek, A., Senff, C. J., Senum, G., Setyan, A., Shilling, J. E., Shrivastava, M., Song, C., Springston, S. R., Subramanian, R., Suski, K., Tomlinson, J., Volkamer, R., Wallace, H. W., Wang, J., Weickmann, A. M., Worsnop, D. R., Yu, X.-Y., Zelenyuk, A., and Zhang, Q.: Overview of the 2010 Carbonaceous Aerosols and Radiative Effects Study (CARES), Atmos. Chem. Phys., 12, 7647-7687, doi:10.5194/acp-12-7647-2012, 2012. 